\title{
PHOTOPROTECTION REVISITED: Genetic and Molecular Approaches
}

\author{
Krishna K. Niyogi \\ Department of Plant and Microbial Biology, University of California, Berkeley, \\ California 94720-3102; e-mail: niyogi@nature.berkeley.edu
}

KEY WORDS: antioxidant, oxidative stress, photosynthesis, photoinhibition, thermal dissipation

\begin{abstract}
The involvement of excited and highly reactive intermediates in oxygenic photosynthesis poses unique problems for algae and plants in terms of potential oxidative damage to the photosynthetic apparatus. Photoprotective processes prevent or minimize generation of oxidizing molecules, scavenge reactive oxygen species efficiently, and repair damage that inevitably occurs. This review summarizes several photoprotective mechanisms operating within chloroplasts of plants and green algae. The recent use of genetic and molecular biological approaches is providing new insights into photoprotection, especially with respect to thermal dissipation of excess absorbed light energy, alternative electron transport pathways, chloroplast antioxidant systems, and repair of photosystem II.
\end{abstract}

\section{CONTENTS}

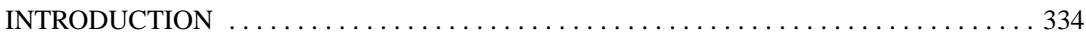

PHOTO-OXIDATIVE DAMAGE TO THE PHOTOSYNTHETIC APPARATUS . . . . . . . . 335

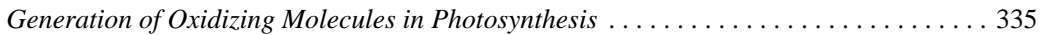

Targets of Photo-Oxidative Damage . . . . . . . . . . . . . . . . . . . . . . . . . 340

ADJUSTMENT OF LIGHT-HARVESTING ANTENNA SIZE . . . . . . . . . . 340

THERMAL DISSIPATION OF EXCESS ABSORBED LIGHT ENERGY . . . . . . . . 341

PHOTOPROTECTION THROUGH PHOTOCHEMISTRY . . . . . . . . . . . . . . . . . . 344

Assimilatory Linear Electron Transport . . . . . . . . . . . . . . . . . . . . . . . . . . . . . . 344

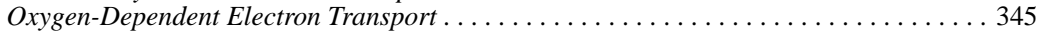

Cyclic Electron Transport . ................................... 346

SCAVENGING OF REACTIVE OXYGEN SPECIES $\ldots \ldots \ldots \ldots \ldots \ldots \ldots \ldots \ldots \ldots \ldots \ldots$

Antioxidant Molecules . . . . . . . . . . . . . . . . . . . . . . . . . . . . . . . 347

Scavenging Enzymes . . . . . . . . . . . . . . . . . . . . . . . . . . . . . . . . 349 


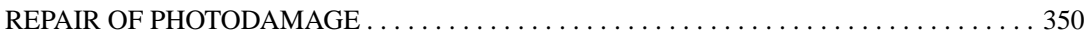

\section{INTRODUCTION}

Light is required for photosynthesis, yet plants need protection from light. Photosynthesis inevitably generates highly reactive intermediates and byproducts that can cause oxidative damage to the photosynthetic apparatus $(16,58)$. This photo-oxidative damage, if not repaired, decreases the efficiency and/or maximum rate of photosynthesis, termed "photoinhibition" (89; reviewed in $13,98,118,129)$.

Oxygenic photosynthetic organisms have evolved multiple photoprotective mechanisms to cope with the potentially damaging effects of light, as diagrammed in Figure 1. Some algae and plants avoid absorption of excessive light by movement of leaves, cells (negative phototaxis), or chloroplasts. Within the chloroplast, regulation of photosynthetic light harvesting and electron transport

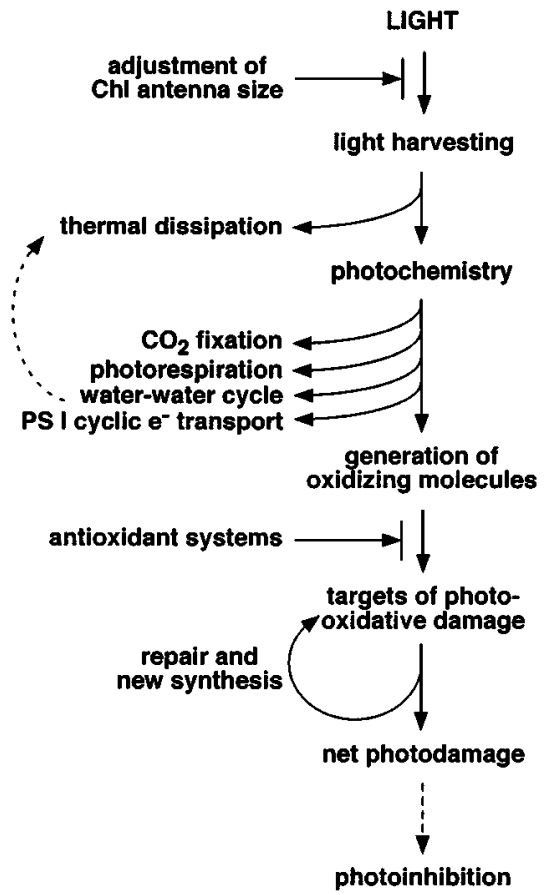

Figure 1 Schematic diagram of photoprotective processes occurring within chloroplasts. 
balances the absorption and utilization of light energy. For example, adjustments in light-harvesting antenna size and photosynthetic capacity can decrease light absorption and increase light utilization, respectively, during relatively long-term acclimation to excessive light. Alternative electron transport pathways and thermal dissipation can also help to remove excess absorbed light energy from the photosynthetic apparatus. Numerous antioxidant molecules and scavenging enzymes are present to deal with the inevitable generation of reactive molecules, especially reactive oxygen species. However, despite these photoprotective defenses, damage to the photosynthetic machinery still occurs, necessitating turnover and replacement of damaged proteins. The overall goal of photoprotection is, therefore, to prevent net damage from occurring.

Because of its importance for maintaining photosynthesis and ultimately for survival of photosynthetic organisms in many natural environments, photoprotection has long been a topic of considerable interest in plant physiology and biochemistry. The general subject of photoprotection, as well as several specific photoprotective processes, have been extensively reviewed $(9,13,18,31,37$, $47-49,51,57,65,76,77,98,112,118,128)$, so one might ask why the topic needs to be "revisited." Although genetic methods have long been used in analysis of photosynthesis $(95,142)$, only recently has there been widespread use of genetic and molecular techniques to dissect specific processes involved in photoprotection. The roles of specific cloned genes are being tested through reverse genetics, and classical (forward) genetics is uncovering new mutants and providing insights into the complexity of photoprotection. This article reviews several photoprotective processes that occur within chloroplasts of eukaryotic photosynthetic organisms, with a particular emphasis on the use of molecular and genetic approaches in intact green algae and plants. Space constraints direct my focus to results obtained with the most commonly used model organisms with good molecular genetics, the green alga Chlamydomonas reinhardtii (Table 1) and the $\mathrm{C} 3$ vascular plants Arabidopsis thaliana and tobacco (Table 2).

\section{PHOTO-OXIDATIVE DAMAGE TO THE PHOTOSYNTHETIC APPARATUS}

Before discussing specific photoprotective mechanisms, I briefly summarize the types of oxidizing molecules that are involved in damaging the photosynthetic machinery.

\section{Generation of Oxidizing Molecules in Photosynthesis}

Because of the large differences in redox potential between reactants and products and the involvement of excited intermediates, oxygenic photosynthesis 
Table 1 Summary of Chlamydomonas mutants affecting photoprotection in the chloroplast

\begin{tabular}{|c|c|c|c|c|}
\hline $\begin{array}{l}\text { Photoprotective } \\
\text { system }\end{array}$ & Mutant & Description & $\begin{array}{c}\text { Photoprotection } \\
\text { phenotype }\end{array}$ & Reference \\
\hline \multirow{6}{*}{$\begin{array}{l}\text { Thermal } \\
\text { dissipation and } \\
\text { xanthophylls }\end{array}$} & $n p q 1$ & Lacks zeaxanthin in $\mathrm{HL}^{\mathrm{a}}$ & $\begin{array}{l}\text { Partly NPQ-deficient; } \\
\text { grows in HL }\end{array}$ & 109 \\
\hline & $n p q 2$ & $\begin{array}{l}\text { Accumulates zeaxanthin; } \\
\text { lacks antheraxanthin, } \\
\text { violaxanthin, and } \\
\text { neoxanthin }\end{array}$ & $\begin{array}{l}\text { Faster induction of NPQ; } \\
\text { grows in } \mathrm{HL}\end{array}$ & 109 \\
\hline & lorl & $\begin{array}{l}\text { Lacks lutein and } \\
\text { loroxanthin }\end{array}$ & $\begin{array}{l}\text { Partly NPQ-deficient; } \\
\text { grows in HL }\end{array}$ & 38,110 \\
\hline & npql lorl & $\begin{array}{l}\text { Lacks zeaxanthin in HL; } \\
\text { lacks lutein and } \\
\text { loroxanthin }\end{array}$ & $\begin{array}{l}\text { NPQ-deficient; } \\
\text { sensitive to HL }\end{array}$ & 110 \\
\hline & $n p q 4$ & Normal xanthophylls & $\begin{array}{l}\text { NPQ-deficient; } \\
\text { grows in HL }\end{array}$ & $\begin{array}{l}\text { D Elrad, KK Niyogi } \\
\text { \& AR Grossman, } \\
\text { unpublished results }\end{array}$ \\
\hline & npq2 lorl & $\begin{array}{l}\text { Accumulates zeaxanthin; } \\
\text { lacks antheraxanthin, } \\
\text { violaxanthin, } \\
\text { neoxanthin, lutein, } \\
\text { and loroxanthin }\end{array}$ & Grows in $\mathrm{HL}$ & $\begin{array}{l}\text { KK Niyogi, } \\
\text { unpublished results }\end{array}$ \\
\hline $\begin{array}{l}\text { Water-water } \\
\text { cycle and } \\
\text { scavenging } \\
\text { enzymes }\end{array}$ & PAR19 & Overexpresses FeSOD & n.d. ${ }^{b}$ & 85 \\
\hline \multirow[t]{3}{*}{ PS II repair } & $s r / s p r$ & $\begin{array}{l}\text { Deficient in chloroplast } \\
\text { protein synthesis }\end{array}$ & Sensitive to $\mathrm{HL}$ & 73 \\
\hline & $\operatorname{ag} 16.2$ & Accumulates D1 protein & Sensitive to $\mathrm{HL}$ & 158 \\
\hline & psbT $\Delta$ & Deficient in PS II in HL & Sensitive to $\mathrm{HL}$ & 105 \\
\hline
\end{tabular}

${ }^{\text {a}}$ High light.

${ }^{\mathrm{b}}$ Not determined.

poses unique problems for algae and plants with respect to the generation of reactive oxygen species and other oxidizing molecules. Potentially damaging molecules are generated at three major sites in the photosynthetic apparatus: the light-harvesting complex (LHC) associated with photosystem (PS) II, the PS II reaction center, and the PS I acceptor side.

Chlorophyll (Chl) molecules are critical participants in light-harvesting and electron transfer reactions in photosynthesis, but $\mathrm{Chl}$ can act as a potent endogenous photosensitizer in algae and plants. Absorption of light causes $\mathrm{Chl}$ to enter the singlet excited state $\left({ }^{1} \mathrm{Chl}\right)$, and the excitation energy is rapidly transferred $(<\mathrm{ps}$ time scale) between neighboring Chls in the LHC by resonance transfer. Before excitation energy is trapped in the reaction center, triplet $\mathrm{Chl}\left({ }^{3} \mathrm{Chl}\right)$ can be formed from ${ }^{1} \mathrm{Chl}$ through intersystem crossing. This is an inherent physical property of ${ }^{1} \mathrm{Chl}(121)$, and the yield of ${ }^{3} \mathrm{Chl}$ formation 
depends on the average lifetime of ${ }^{1} \mathrm{Chl}(\sim$ ns time scale) in the antenna (58). In contrast to ${ }^{1} \mathrm{Chl},{ }^{3} \mathrm{Chl}$ is relatively long-lived ( $\sim$ ms time scale) and can interact with $\mathrm{O}_{2}$ to produce singlet oxygen $\left({ }^{1} \mathrm{O}_{2}\right)(56)$. Because the average lifetime of ${ }^{1} \mathrm{Chl}$ in the PS II LHC is several times longer than in the PS I LHC, the potential for generation of ${ }^{1} \mathrm{O}_{2}$ is greater in the PS II LHC.

In the PS II reaction center, trapping of excitation energy involves a primary charge separation between a Chl dimer (P680) and a pheophytin molecule (Pheo) that are bound to the D1 reaction center protein. The $\mathrm{P} 680^{+} / \mathrm{Pheo}^{-}$ radical pair is reversible $(44,134)$, and the charge recombination (and other backreactions in PS II) can generate triplet P680 ( $\left.{ }^{3} \mathrm{P} 680\right)(11,13,115,148)$. As in the LHC, energy exchange between ${ }^{3} \mathrm{P} 680$ and $\mathrm{O}_{2}$ results in formation of ${ }^{1} \mathrm{O}_{2}$. The $\mathrm{P} 680^{+} / \mathrm{Pheo}^{-}$charge separation can be stabilized upon electron transfer from $\mathrm{Pheo}^{-}$to the quinone acceptor $\mathrm{Q}_{\mathrm{A}}$, and $\mathrm{P} 60^{+}$is subsequently reduced by an electron derived from the oxidation of $\mathrm{H}_{2} \mathrm{O}$ via the secondary donor $\mathrm{Y}_{Z}$ (tyrosine 161 of the $\mathrm{D} 1$ protein). Although the very high oxidizing potential of $\mathrm{P}_{680}{ }^{+}$and $\mathrm{Y}_{\mathrm{Z}}^{+}$enables plants to use $\mathrm{H}_{2} \mathrm{O}$ as an electron donor, $\mathrm{P} 680^{+}$and $\mathrm{Y}_{\mathrm{Z}}^{+}$ themselves are also capable of oxidizing nearby pigments and proteins $(11,13)$.

In PS I, charge separation occurring between P700 and the primary acceptor $\mathrm{Chl} \mathrm{A}_{0}$ is stabilized by subsequent electron transfer to secondary acceptors, the phylloquinone $A_{1}$ and three iron-sulfur clusters $\left(F_{X}, F_{A}\right.$, and $\left.F_{B}\right)$. In contrast to $\mathrm{P} 680^{+}, \mathrm{P}_{700}{ }^{+}$is less oxidizing and relatively stable; in fact, $\mathrm{P} 700^{+}$is a very efficient quencher of excitation energy from the PS I LHC $(44,121)$. However, the acceptor side of PS I, which has a redox potential low enough to reduce $\mathrm{NADP}^{+}$via ferredoxin, is also capable of reducing $\mathrm{O}_{2}$ to the superoxide anion radical $\left(\mathrm{O}_{2}^{-}\right)$(102). $\mathrm{O}_{2}^{-}$can be metabolized to $\mathrm{H}_{2} \mathrm{O}_{2}$, and a metal-catalyzed Haber-Weiss or Fenton reaction can lead to production of the hydroxyl radical $(\mathrm{OH} \cdot)$, an extremely toxic type of reactive oxygen species (16).

Generation of these oxidizing molecules occurs at all light intensities, but when absorbed light energy exceeds the capacity for light energy utilization through photosynthesis, the potential for photo-oxidative damage is exacerbated. In excessive light, accumulation of excitation energy in the PS II LHC will increase the average lifetime of ${ }^{1} \mathrm{Chl}$, thereby increasing the yield of ${ }^{3} \mathrm{Chl}$ and ${ }^{1} \mathrm{O}_{2}$. Higher excitation pressure in PS II can increase the frequency of direct damage by $\mathrm{P}_{680^{+}}$and formation of ${ }^{1} \mathrm{O}_{2}$ as a result of $\mathrm{P} 680^{+} / \mathrm{Pheo}^{-}$recombination. Furthermore, the high $\Delta \mathrm{pH}$ that builds up in excessive light can inhibit electron donation to $\mathrm{P} 680^{+}$from the oxygen-evolving complex, resulting in longer-lived $\mathrm{P} 60^{+}$and/or $\mathrm{Y}_{\mathrm{Z}}^{+}$. Overreduction of the PS I acceptor side in excessive light favors direct reduction of $\mathrm{O}_{2}$ to form $\mathrm{O}_{2}^{-}$. Analysis of transgenic tobacco plants with reduced levels of cytochrome $b_{6} / f$ complex has pointed to the involvement of lumen acidification and/or overreduction of the PS I acceptor side in photoinhibition (80). 


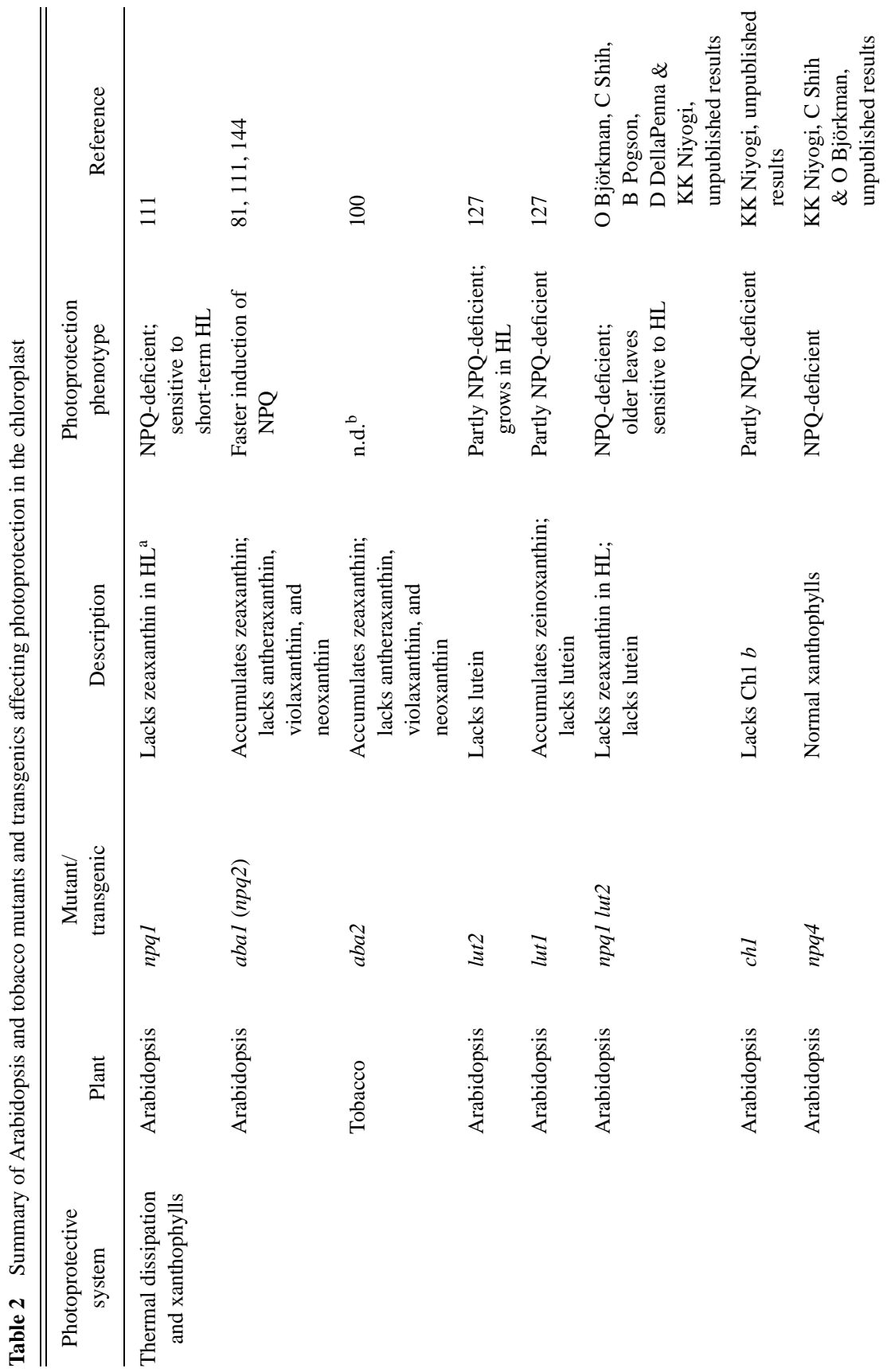




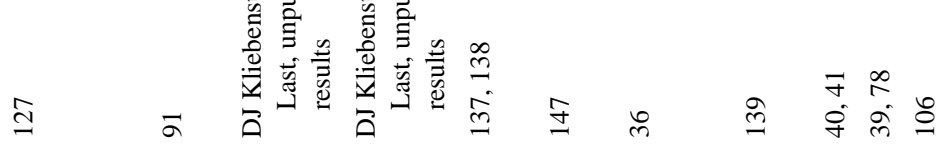

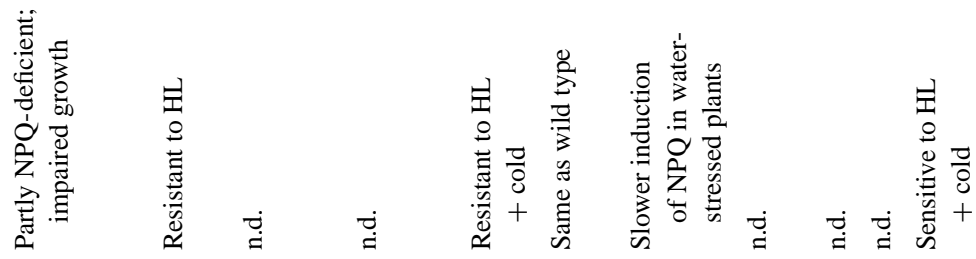

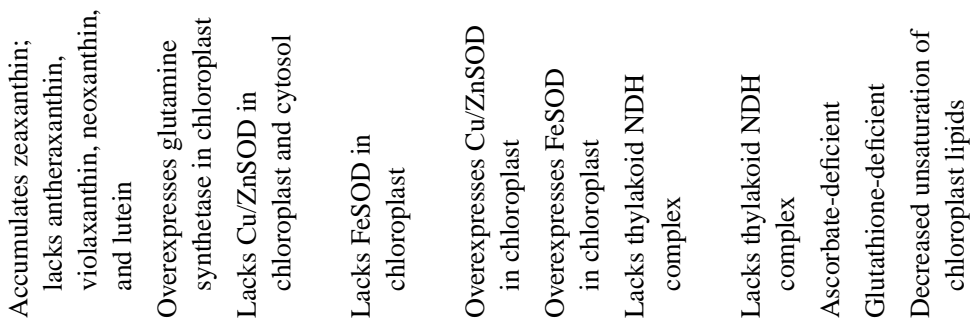

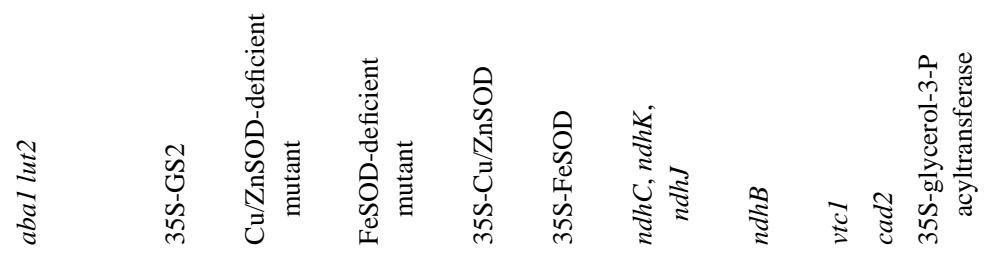

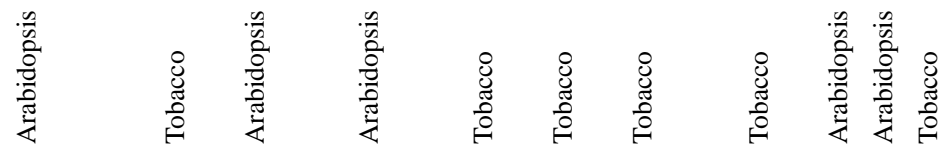

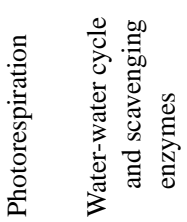

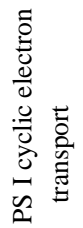




\section{Targets of Photo-Oxidative Damage}

Although the exact mechanism(s) of damage has not been determined, PS II is a major target of photo-oxidative damage $(10,11,13,115)$. Interestingly, photoinhibition of PS II, measured as a decrease in either the flash yield of $\mathrm{O}_{2}$ evolution or the Chl fluorescence parameter $F_{\mathrm{v}} / F_{\mathrm{m}}$, seems to depend on the number of absorbed photons rather than the rate of photon absorption. This implies that there is a constant probability of photodamage for each absorbed photon during conditions of steady-state photosynthesis $(122,123)$. However, the probability of photodamage can be modulated by changes in Chl antenna size and rate of electron transport $(20,124)$, which alter the excitation pressure on PS II (79) at a given light intensity.

Generation of ${ }^{1} \mathrm{O}_{2}$ within the LHCs can potentially lead to oxidation of lipids, proteins, and pigments in the immediate vicinity (87). Thylakoid membrane lipids are especially susceptible to damage by ${ }^{1} \mathrm{O}_{2}$ because of the abundance of unsaturated fatty acid side chains. Reaction between ${ }^{1} \mathrm{O}_{2}$ and these lipids produces hydroperoxides and initiates peroxyl radical chain reactions in the thylakoid membrane. Generation of ${ }^{1} \mathrm{O}_{2}$ and/or P680 ${ }^{+}$in the PS II reaction center can result in damage to lipids, critical pigment cofactors, and protein subunits associated with PS II, especially the D1 protein, resulting in photooxidative inactivation of entire reaction centers $(13,18)$.

On the acceptor (stromal) side of PS I, the targets of oxidative damage by $\mathrm{O}_{2}^{-}$, $\mathrm{H}_{2} \mathrm{O}_{2}$, and $\mathrm{OH}$. include key enzymes of photosynthetic carbon metabolism such as phosphoribulokinase, fructose-1,6-bisphosphatase, and NADP-glyceraldehyde-3-phosphate dehydrogenase $(16,84)$. Photoinhibition due to damage to the PS I reaction center itself can be observed under some circumstances, especially during chilling stress (reviewed in 143).

\section{ADJUSTMENT OF LIGHT-HARVESTING ANTENNA SIZE}

Changes in the sizes of the Chl antennae associated with PS II and PS I are involved in balancing light absorption and utilization (reviewed in 7, 103). During long-term acclimation to growth in different light intensities, changes in antenna size are due to changes in LHC gene expression $(54,101,150)$ and/or LHC protein degradation (96). No mutants affecting acclimatory changes in $\mathrm{Chl}$ antenna size have yet been reported.

Short-term alteration of the relative antenna sizes of PS II and PS I can occur because of state transitions. According to the state transition model (reviewed in 2), overexcitation of PS II relative to PS I reduces the plastoquinone pool and activates a kinase that phosphorylates the peripheral LHC associated with PS II. Subsequent detachment of phospho-LHC from PS II decreases the effective size 
of the PS II antenna, and the phospho-LHC may then transfer excitation energy to PS I. Although the state transition is often suggested to be photoprotective (for example, see 8,13), there is no convincing evidence for its role in photoprotection, at least in excessive light. In fact, the LHC kinase system seems to be inactivated in high light $(46,130,136)$. Mutants affecting the state transition would be useful to test the hypothesis.

\section{THERMAL DISSIPATION OF EXCESS ABSORBED LIGHT ENERGY}

In excessive light, an increase in the thylakoid $\Delta \mathrm{pH}$ regulates PS II light harvesting by triggering the dissipation of excess absorbed light energy as heat (reviewed in $31,47,48,49,51,65,76,77)$. Over $75 \%$ of absorbed photons can be eliminated by this process of thermal dissipation (50), which involves de-excitation of ${ }^{1} \mathrm{Chl}$ and which is measured (and often referred to) as nonphotochemical quenching of Chl fluorescence (NPQ). Thermal dissipation is thought to protect photosynthesis by $(a)$ decreasing the lifetime of ${ }^{1} \mathrm{Chl}$ to minimize generation of ${ }^{1} \mathrm{O}_{2}$ in the PS II LHC and reaction center, $(b)$ preventing overacidification of the lumen and generation of long-lived $\mathrm{P} 680^{+}$, and $(c)$ decreasing the rate of $\mathrm{O}_{2}$ reduction by PS I. Although thermal dissipation is usually reversible within seconds or minutes, sustained thermal dissipation (also called qI) can be manifested as photoinhibition, which may actually be due to a photoprotective mechanism $(52,77,82,92,116)$. I focus on the rapidly reversible ( $\mathrm{pH}$-dependent) type of thermal dissipation (also called $\mathrm{qE}$ ) that predominates under most circumstances.

$\mathrm{pH}$-dependent thermal dissipation occurs in the PS II antenna pigment bed and involves specific de-epoxidized xanthophyll pigments (31, 47-49, 51; $65,76,77)$. The increase in the thylakoid $\Delta \mathrm{pH}$ in excessive light is thought to result in protonation of specific LHC polypeptides associated with PS II, namely LHCB4 (CP29) and LHCB5 (CP26) $(42,75,151,152)$. The $\Delta \mathrm{pH}$ also activates the enzyme violaxanthin de-epoxidase, which converts violaxanthin associated with the LHCs to zeaxanthin (and antheraxanthin) via the so-called xanthophyll cycle (see Figure 2) $(55,125)$. Binding of zeaxanthin and protons to the LHC may cause a conformational change, monitored by an absorbance change at $535 \mathrm{~nm}(23-25,132)$, that is necessary for thermal dissipation. The actual mechanism of ${ }^{1} \mathrm{Chl}$ de-excitation may involve a direct transfer of energy from Chl to zeaxanthin $(37,62,120)$. Alternatively, xanthophylls (and protons) may act as allosteric effectors of LHC structure, leading to "concentration quenching" by Chls (77) or quenching via Chl dimer formation (42).

Mutants of Chlamydomonas and Arabidopsis that affect thermal dissipation have been isolated by video imaging of Chl fluorescence quenching (109, 


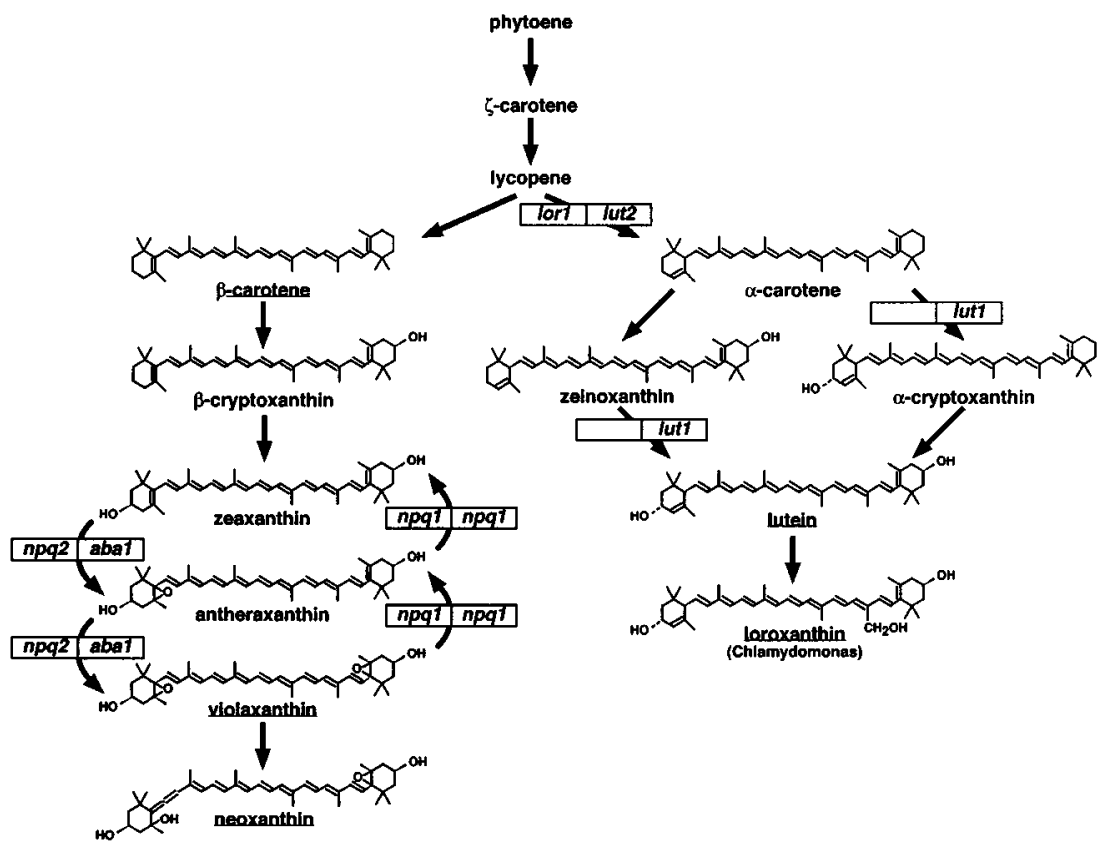

Figure 2 The pathway for carotenoid biosynthesis in green algae and plants. The steps blocked in mutants of Chlamydomonas and Arabidopsis are designated by the boxes, with the names of the mutants shown in the left half of the box for Chlamydomonas and the right half for Arabidopsis. Strains defective in some of these reactions have also been identified in Scenedesmus obliquus $(26,28)$. The xanthophyll cycle that operates in the $\beta$-carotene branch of the pathway involves zeaxanthin, antheraxanthin, and violaxanthin. The carotenoids that normally accumulate in the chloroplast are underlined; zeaxanthin accumulates in excessive light.

111, 140). Characterization of mutants affected in xanthophyll metabolism (Figure 2) has confirmed a role for zeaxanthin in thermal dissipation (81, $109,111,144)$. The npq 2 mutants of Chlamydomonas and Arabidopsis, together with the existing abal mutant of Arabidopsis (90) and aba2 mutant of tobacco (100), are defective in zeaxanthin epoxidase activity; they accumulate zeaxanthin and contain only trace amounts of antheraxanthin, violaxanthin, and neoxanthin $(53,100,109,111,131)$. The constitutive presence of zeaxanthin in the PS II LHCs of $n p q 2$ and abal mutants is not sufficient for thermal dissipation, which also requires the $\Delta \mathrm{pH}$. However, induction of NPQ by illumination with high light is more rapid in the mutants compared to wild type $(81,109,111,144)$, presumably because it is driven solely by the build-up of the $\Delta \mathrm{pH}$. During short-term illumination with high light, some abal mutants exhibited the same sensitivity to photoinhibition as the wild type 
(81), whereas an abal mutant with a different allele appeared more sensitive (144).

The Chlamydomonas npq1 mutant, which is unable to convert violaxanthin to zeaxanthin, is partially defective in NPQ but retains substantial, pH-dependent NPQ, which suggests that some but not all thermal dissipation depends on operation of the xanthophyll cycle (109). Characterization of the lorl mutant, which lacks xanthophylls derived from $\alpha$-carotene $(38,110)$, indicates a possible role for lutein in thermal dissipation (110). Neither npq1 nor lorl is particularly sensitive to photoinhibition during growth in high light. However, an npq1 lorl double mutant lacks almost all $\mathrm{pH}$-dependent NPQ and is very susceptible to photo-oxidative bleaching in high light. Although this result seems to provide evidence for the importance of thermal dissipation for photoprotection in vivo, the phenotype is complicated by the fact that xanthophylls are also involved in quenching of ${ }^{3} \mathrm{Chl}$ and ${ }^{1} \mathrm{O}_{2}$ and inhibition of lipid peroxidation, as described below. Another mutant, npq4, lacks NPQ but has normal xanthophyll composition. It is able to survive in high light, suggesting that thermal dissipation itself is not required for photoprotection (D Elrad, KK Niyogi \& AR Grossman, unpublished results).

Results with Arabidopsis xanthophyll mutants, although generally similar to results with Chlamydomonas, revealed that the relative contributions of different xanthophylls to thermal dissipation vary in different organisms. Like npql of Chlamydomonas, Arabidopsis npql mutants are unable to convert violaxanthin to zeaxanthin in high light. Genetic and molecular analyses (111) demonstrated that the phenotype of npql is due to a recessive mutation in the Arabidopsis violaxanthin de-epoxidase gene (35). In contrast to the results with Chlamydomonas, induction of $\mathrm{pH}$-dependent thermal dissipation in the Arabidopsis $n p q 1$ mutant is almost completely inhibited, suggesting that most of the thermal dissipation in Arabidopsis depends on de-epoxidation of violaxanthin (111). Leaves of $n p q 1$ plants sustain more photoinhibition than wild type following short-term illumination with high light, in agreement with experiments that used dithiothreitol as an inhibitor of violaxanthin de-epoxidase in detached leaves $(23,156)$. However, growth of $n p q 1$ plants that are acclimated to high light is not noticeably different from that of the wild type, which suggests that, in the long term, other photoprotective processes can compensate for the defect in npql (111).

As in Chlamydomonas, analysis of Arabidopsis mutants lacking lutein suggests that the residual $\mathrm{pH}$-dependent NPQ in $n p q 1$ may be attributable to a contribution of lutein-dependent NPQ (127). The lut2 mutant, which lacks lutein owing to a mutation in the lycopene $\varepsilon$-cyclase gene (126), exhibits slower induction and a lower maximum extent of NPQ (127), and an npql lut2 double mutant lacks almost all pH-dependent NPQ (O Björkman, C Shih, B Pogson, 
D DellaPenna \& KK Niyogi, unpublished results). Lutein may have a direct role in thermal dissipation, or the lack of lutein in lorl and lut 2 mutants may have an indirect effect. In mutants lacking lutein, zeaxanthin may be sequestered in binding sites that are normally occupied by lutein but inactive in thermal dissipation, thereby lowering the relative effectiveness of zeaxanthin (AM Gilmore, KK Niyogi \& O Björkman, unpublished results).

The requirement for different proteins in the PS II LHC for thermal dissipation has been addressed using mutants lacking $\mathrm{Chl} b$. These mutants, such as barley chlorina 2 and Arabidopsis chl, are impaired in the synthesis and/or assembly of LHC proteins, especially the peripheral LHC of PS II, due to the lack of Chl $b(32,93,108)$. Measurements of NPQ and Chl fluorescence lifetime components in these mutants suggest that only the minor LHC proteins, such as LHCB4 and LHCB5, are necessary for thermal dissipation, although maximal NPQ requires the presence of the entire LHC $(12,34,66,68,69$, 97; KK Niyogi, unpublished results). To test the role of specific LHC proteins in thermal dissipation, mutants or antisense plants affecting individual genes will be very useful.

Several other $n p q$ mutants exhibit normal pigment composition and xanthophyll interconversions. These mutants presumably identify factors besides the $\Delta \mathrm{pH}$ and xanthophylls (perhaps LHC components) that are required for thermal dissipation in Chlamydomonas (109; D Elrad, KK Niyogi \& AR Grossman, unpublished results) and Arabidopsis (KK Niyogi, C Shih \& O Björkman, unpublished results). For example, the Arabidopsis npq4 mutant exhibits the same lack of NPQ as an npql lut2 double mutant, which suggests that it is defective in all $\mathrm{pH}$ - and xanthophyll-dependent thermal dissipation, yet it is indistinguishable from wild type in terms of xanthophyll interconversion and growth in low light. In addition, $n p q 4$ lacks the absorbance change that presumably reflects the conformational change that is necessary for thermal dissipation (KK Niyogi, C Shih \& O Björkman, unpublished results). Determination of the molecular basis for mutations such as $n p q 4$ will likely provide new insights into the molecular mechanism of thermal dissipation.

\section{PHOTOPROTECTION THROUGH PHOTOCHEMISTRY}

\section{Assimilatory Linear Electron Transport}

Much of the light energy absorbed by the LHCs is utilized through photochemistry that drives linear electron transport from $\mathrm{H}_{2} \mathrm{O}$ to $\mathrm{NADPH}$, resulting in $\mathrm{O}_{2}$ evolution and reduction of $\mathrm{CO}_{2}, \mathrm{NO}_{3}^{-}$, and $\mathrm{SO}_{4}^{2-}$. The maximum rate of photosynthesis is a dynamic parameter that can be altered during acclimation to growth in different light environments (reviewed in 30,37) through changes in enzyme activities and gene expression. These acclimation responses generally occur during a period of several days, and there are few or no molecular 
genetic data that address the importance of long-term acclimation responses for photoprotection.

\section{Oxygen-Dependent Electron Transport}

There is abundant evidence that nonassimilatory electron transport to oxygen plays an important role in consuming excess excitation energy. Oxygen can function as an electron acceptor either through the oxygenase reaction catalyzed by Rubisco (photorespiration) or by direct reduction of oxygen by electrons on the acceptor side of PS I (102), and there is much debate about which process is more important for photoprotection (for example, see 22, 71, 119, 124, 155).

PHOTORESPIRATION In C3 plants, especially under conditions of $\mathrm{CO}_{2}$ limitation, photorespiratory oxygen metabolism is capable of maintaining considerable linear electron transport and utilization of light energy (reviewed in 117). The role of photorespiration in photoprotection can be conveniently assessed by varying the gas composition to inhibit the oxygenation reaction of Rubisco. Blocking photorespiration with mutations or inhibitors leads to inhibition of photosynthesis and photo-oxidative damage, and the cause of inhibition varies (14). Accumulation of photorespiratory metabolites or depletion of carbon intermediates can inhibit the Calvin cycle and shut down the photochemical sink for excitation energy. To assess the importance of photorespiration without the complications of accumulating toxic intermediates, mutants of Rubisco that lack oxygenase activity would be required.

Manipulation of glutamine synthetase activity, a rate-limiting step in photorespiratory metabolism, in transgenic tobacco plants has provided additional evidence for the role of photorespiration in photoprotection (91). Antisense plants with less glutamine synthetase are more sensitive to photo-oxidation under conditions of $\mathrm{CO}_{2}$ limitation because of accumulation of photorespiratory $\mathrm{NH}_{3}$, in agreement with previous results with mutant barley plants lacking glutamine synthetase (149). In contrast, plants that overexpress glutamine synthetase have a higher capacity for photorespiration and are more resistant to photoinhibition and photo-oxidative damage (91).

PHOTOREDUCTION OF OXYGEN BY PHOTOSYSTEM I Direct reduction of $\mathrm{O}_{2}$ by PS I is the first step in an alternative electron transport pathway that has been variously termed pseudocyclic electron transport, the Mehler-ascorbate peroxidase reaction, and the water-water cycle. Because a comprehensive review of this pathway appears in this volume (17), it is only briefly outlined here. $\mathrm{The}_{2}^{-}$ produced on the acceptor side of PS I by reduction of $\mathrm{O}_{2}$ is efficiently metabolized by thylakoid-bound isozymes of superoxide dismutase (SOD) and ascorbate peroxidase (APX) to generate $\mathrm{H}_{2} \mathrm{O}$ and monodehydroascorbate, which can itself be reduced directly by PS I to regenerate ascorbate (15-17). Thus the four 
electrons generated by oxidation of $\mathrm{H}_{2} \mathrm{O}$ by PS II are consumed by reduction of $\mathrm{O}_{2}$ to $\mathrm{H}_{2} \mathrm{O}$ by PS I. This pseudocyclic pathway generates a $\Delta \mathrm{pH}$ for ATP synthesis, but neither NADPH nor net $\mathrm{O}_{2}$ is produced.

Like photorespiration, the water-water cycle may help to dissipate excitation energy through electron transport. However, the capacity of this pathway to support electron transport is unclear; estimates range between $10 \%$ and $30 \%$ of normal linear electron transport in algae and C3 plants $(22,99,119)$. The pathway may also be involved in maintaining a $\Delta \mathrm{pH}$ necessary for thermal dissipation of excess absorbed light energy (135).

Genes encoding SOD and APX have been identified from several plants, including Arabidopsis $(83,86)$, and this should enable dissection of the waterwater cycle by analysis of antisense plants or mutants. However, the mutant analysis will be complicated by the dual roles of these enzymes in scavenging reactive oxygen intermediates and in electron transport.

\section{Cyclic Electron Transport}

Within PS II, cyclic electron transport pathways, possibly involving cytochrome $b_{559}$, have been suggested to dissipate excitation energy (reviewed in 37,154 ), but convincing evidence for their occurrence in vivo is lacking. Cytochrome $b_{559}$ may function to oxidize $\mathrm{Pheo}^{-}$or reduce $\mathrm{P}_{680^{+}}$to protect against photodamage to PS II (154). Site-directed mutagenesis of the chloroplast genes encoding the $\alpha$ and $\beta$ polypeptides of cytochrome $b_{559}$ in Chlamydomonas $(1,107)$ will be useful to dissect the possible role of this cytochrome in cyclic electron transport and photoprotection.

Cyclic electron transport around PS I is also suggested to have an important role in photoprotection. In addition to dissipating energy absorbed by PS I, cyclic electron transport may be involved in generating or maintaining the $\Delta \mathrm{pH}$ that is necessary for downregulation of PS II by thermal dissipation of excess absorbed light energy (72). Biochemical approaches have led to the conclusion that there are at least two pathways of PS I cyclic electron transport, one involving a ferredoxin-plastoquinone oxidoreductase (FQR) and the other involving an NADPH/NADH dehydrogenase (NDH) complex (reviewed in 21). The FQR has not yet been identified, although the PsaE subunit of PS I is possibly involved. The NDH pathway involves a protein complex bound to the thylakoid membrane that is homologous to the NADH dehydrogenase complex I of mitochondria. Several subunits of this complex are encoded by genes on the chloroplast genome of many plants (reviewed in 63).

Mutants affecting the NDH complex have been generated by disrupting $n d h$ genes in the chloroplast genome of tobacco by homologous recombination $(36,88,139)$. These mutants have no obvious phenotype under normal growth conditions. However, measurements of Chl fluorescence and PS I reduction 
kinetics revealed that cyclic electron transport is partially impaired $(36,139)$. Induction of thermal dissipation upon sudden illumination was slightly delayed in mutants subjected to water stress, consistent with the idea that PS I cyclic electron transport is involved in maintaining a $\Delta \mathrm{pH}$ for thermal dissipation (36). Thorough examination of photoprotection in these mutants under less favorable growth conditions should be very informative, although the existence of other cyclic pathways may complicate interpretations.

\section{SCAVENGING OF REACTIVE OXYGEN SPECIES}

Several antioxidant systems in the chloroplast can scavenge reactive oxygen species that are inevitably generated by photosynthesis $(15,57,128)$. In many cases, increases in antioxidant molecules and enzymes have been observed during acclimation to excessive light (for example, see 67), and the specific roles of these molecules are starting to be tested using mutant and transgenic organisms $(3-5,57)$.

\section{Antioxidant Molecules}

CAROTENOIDS Carotenoids, including the xanthophylls, are membrane-bound antioxidants that can quench ${ }^{3} \mathrm{Chl}$ and ${ }^{1} \mathrm{O}_{2}$, inhibit lipid peroxidation, and stabilize membranes (reviewed in 51,60,61,70). The genes and enzymes involved in their biosynthesis have been reviewed recently in this series (43). Xanthophylls bound to the LHC proteins are located in close proximity to Chl for efficient quenching of ${ }^{3} \mathrm{Chl}$ and ${ }^{1} \mathrm{O}_{2}$ (94). $\beta$-carotene in the PS II reaction center quenches ${ }^{1} \mathrm{O}_{2}$ produced from interaction of ${ }^{3} \mathrm{P} 680$ and $\mathrm{O}_{2}$ but is not thought to quench ${ }^{3} \mathrm{P} 680$ itself (145). As discussed above, specific xanthophylls are also involved in quenching of ${ }^{1} \mathrm{Chl}$ during thermal dissipation.

Carotenoids in general have essential functions in photosynthesis and photoprotection, as demonstrated by the bleached phenotypes of algae and plants that are unable to synthesize any carotenoids owing to mutations affecting early steps of carotenoid biosynthesis $(6,133)$. However, characterization of xanthophyll mutants blocked in later steps in the carotenoid pathway (Figure 2) has demonstrated that no single xanthophyll is absolutely required for photoprotection (109-111, 126). For example, Chlamydomonas mutants lacking lutein and loroxanthin (lorl), antheraxanthin, violaxanthin, and neoxanthin (npq2), or zeaxanthin (npql) are all able to grow as well as wild type in high light $(109,110)$.

Eliminating combinations of xanthophylls in double mutants has revealed a redundancy among xanthophylls in terms of photoprotection. Construction of an npql lorl double mutant has demonstrated that accumulation of either zeaxanthin or lutein is necessary for photoprotection and survival of 
Chlamydomonas in high light (110). The light sensitivity of the npql lorl strain probably reflects the multiple roles of specific xanthophylls in photoprotection; quenching of ${ }^{1} \mathrm{Chl},{ }^{1} \mathrm{O}_{2}$, and possibly also inhibition of lipid peroxidation are impaired in the absence of both zeaxanthin and lutein (110). A similar sensitivity to very high light is observed in older leaves of the Arabidopsis npq1 lut2 double mutant, but the photo-oxidative damage is not lethal to the entire plant (O Björkman, C Shih, B Pogson, D DellaPenna \& KK Niyogi, unpublished results).

Zeaxanthin is sufficient for photoprotection. Double mutants of Chlamydomonas (npq2 lorl) and Arabidopsis (abal lut2), as well as the C-2A'-67,3b strain of Scenedesmus obliquus (26), that contain zeaxanthin as the only chloroplast xanthophyll are viable, although the photosynthetic efficiency of the Scenedesmus strain is decreased (27), and growth of the Arabidopsis abal lut 2 is impaired (127). In the case of Chlamydomonas npq 2 lorl, the mutant grows as well as wild type in high light (KK Niyogi, unpublished results). Selective elimination of all the xanthophylls derived from $\beta$-carotene to test whether lutein is sufficient for photoprotection may be difficult using mutants, because the same $\beta$-hydroxylase seems to be involved in synthesis of both zeaxanthin and lutein (43).

TOCOPHEROLS Another important thylakoid membrane antioxidant is $\alpha$-tocopherol (vitamin E), which can physically quench or chemically scavenge ${ }^{1} \mathrm{O}_{2}$, $\mathrm{O}_{2}^{-}$and $\mathrm{OH}$. in the membrane to prevent lipid peroxidation (57). Whereas the xanthophylls are largely bound to proteins, $\alpha$-tocopherol is free in the lipid matrix of the membrane and appears to have a role in controlling membrane fluidity and stability (64). In addition, $\alpha$-tocopherol participates in the efficient termination of lipid peroxidation chain reactions with concomitant formation of its $\alpha$-chromanoxyl radical (64).

Although $\alpha$-tocopherol is the most abundant tocopherol in the chloroplast, other tocopherols such as $\beta$ - and $\gamma$-tocopherols are also present at low levels. The minor tocopherols are intermediates in the synthesis of $\alpha$-tocopherol that differ in the number of methyl groups on the chromanol head group. The relative abundance of the tocopherols $(\alpha>\beta>\gamma)$ parallels their effectiveness as chemical scavengers of reactive oxygen species and as chain reaction terminators (64).

Unfortunately, there are few genetic data that address the importance of specific tocopherols, or tocopherols in general, in photoprotection. A Scenedesmus mutant lacking all tocopherols has been reported (29), but the lesion in the mutant appeared to affect the synthesis of phylloquinones and phytylbenzoquinones in addition to tocopherols (74). The Arabidopsis $p d s 1$ and $p d s 2 \mathrm{mu}-$ tants lack both tocopherols and quinones due to blocks in the biosynthetic 
pathway common to both types of molecules (113). Interestingly, the mutants also lacked carotenoids, uncovering a role for plastoquinone in the desaturation of phytoene (113). A gene encoding one of the later steps of tocopherol biosynthesis has recently been identified in cyanobacteria and Arabidopsis (140a), and application of reverse genetics promises insights into the photoprotective role of specific tocopherols in the near future.

ASCORBATE The soluble antioxidant ascorbate (vitamin C) has a central role in preventing oxidative damage through direct quenching of ${ }^{1} \mathrm{O}_{2}, \mathrm{O}_{2}^{-}$ and $\mathrm{OH}$, in regeneration of $\alpha$-tocopherol from the $\alpha$-chromanoxyl radical, and as a substrate in both the violaxanthin de-epoxidase and APX reactions $(112,141)$. Although ascorbate is very abundant in chloroplasts $(\sim 25 \mathrm{mM})$, the biosynthetic pathway for ascorbate in plants was elucidated only very recently (153), and the importance of ascorbate in photoprotection has not been determined. Ascorbate-deficient mutants affecting the biosynthetic pathway have been identified recently in a screen for ozone-sensitive mutants in Arabidopsis $(40,41)$. One mutant, originally called sozl but renamed vtcl, accumulates approximately $30 \%$ as much ascorbate as wild type. In addition to its ozone sensitivity, the vtcl mutant is more sensitive to exogenous $\mathrm{H}_{2} \mathrm{O}_{2}, \mathrm{SO}_{2}$, and illumination with UV-B, but sensitivity to high light has not yet been examined.

GLUTATHIONE Another important soluble antioxidant in the chloroplast is glutathione, which is capable of detoxifying ${ }^{1} \mathrm{O}_{2}$ and $\mathrm{OH}$. Glutathione protects thiol groups in stromal enzymes, and it is also involved in $\alpha$-tocopherol regeneration and ascorbate regeneration through the glutathione-ascorbate cycle $(16,59)$. Biosynthesis of glutathione proceeds by the reaction of glutamine and cysteine to form $\gamma$-glutamylcysteine, followed by the addition of glycine catalyzed by glutathione synthetase. The Arabidopsis cad 2 mutant is deficient in glutathione (78) owing to a defect in the gene encoding $\gamma$-glutamylcysteine synthetase (39). The level of glutathione in cad 2 leaves is approximately $30 \%$ of that in the wild type. As in the case of the ascorbate-deficient mutant, the sensitivity of $c a d 2$ to photoinhibition remains to be determined.

\section{Scavenging Enzymes}

The enzymes SOD and APX are involved in scavenging reactive oxygen species in the chloroplast. As discussed above, $\mathrm{O}_{2}^{-}$generated by reduction of $\mathrm{O}_{2}$ by PS I is metabolized enzymatically by SOD to produce $\mathrm{H}_{2} \mathrm{O}_{2}$. The subsequent reduction of $\mathrm{H}_{2} \mathrm{O}_{2}$ by APX produces the monodehydroascorbate radical, which can be directly reduced by PS I (via ferredoxin) in the water-water cycle (17). Ascorbate can also be regenerated in the stroma by the set of enzymes comprising the glutathione-ascorbate cycle $(16,59)$. 
Both SOD and APX exist in multiple isoforms within the chloroplast. The SOD isozymes are generally classified according to their active site metal (33): copper/zinc (Cu/ZnSOD), iron (FeSOD), or manganese (MnSOD). Most plants have FeSOD and $\mathrm{Cu} / \mathrm{ZnSOD}$ in their chloroplasts, whereas most algae appear to lack the $\mathrm{Cu} / \mathrm{ZnSOD}$ completely (45). Thylakoid-bound forms of SOD (114) and APX (104) may efficiently detoxify $\mathrm{O}_{2}^{-}$and $\mathrm{H}_{2} \mathrm{O}_{2}$ at their site of production $(16,58)$ and prevent inactivation of Calvin cycle enzymes $(84)$. Soluble forms of SOD and APX react with $\mathrm{O}_{2}^{-}$and $\mathrm{H}_{2} \mathrm{O}_{2}$ that diffuse into the stroma from the thylakoid membrane.

Mutants or antisense plants have the potential to reveal roles of different SODs and APXs in photoprotection. Arabidopsis has at least seven SOD genes: three encoding $\mathrm{Cu} / \mathrm{ZnSOD}$, three encoding FeSOD, and one encoding MnSOD (86). One of the $\mathrm{Cu} / \mathrm{ZnSOD}$ and all three of FeSOD gene products are located in the chloroplast. Mutants that are deficient in expression of plastidic and cytosolic $\mathrm{Cu} / \mathrm{ZnSODs}$ or plastidic FeSODs have been isolated (DJ Kliebenstein \& RL Last, unpublished results), but the phenotypes of these mutants in high light have not been tested. Genes encoding the stromal and thylakoidbound forms of APX have been cloned from Arabidopsis (83), but mutants or transgenic plants with altered expression of chloroplast APX have not yet been reported.

Transgenic plants overexpressing SOD have been generated by several groups, and the results of these experiments were recently reviewed $(3-5,57)$. Photoprotection has been examined specifically in only a few cases. An enhancement of tolerance to a combination of high light and chilling stress has been observed in tobacco plants overexpressing chloroplast $\mathrm{Cu} / \mathrm{ZnSOD}$ $(137,138)$ but not in plants overexpressing chloroplast FeSOD $(147)$. This is consistent with the localization of $\mathrm{Cu} / \mathrm{ZnSOD}$ at the thylakoid membrane where $\mathrm{O}_{2}^{-}$is reduced by PS I (114). However, chloroplast APX activity is induced in the $\mathrm{Cu} / \mathrm{ZnSOD}$ transgenic plants; the combination of increased $\mathrm{Cu} / \mathrm{ZnSOD}$ and APX activities may result in enhanced photoprotection (138). The photoprotection phenotype of a Chlamydomonas mutant that overexpresses chloroplastlocalized FeSOD has not been reported (85).

\section{REPAIR OF PHOTODAMAGE}

Despite multiple lines of defense, damage to the photosynthetic apparatus is an inevitable consequence of oxygenic photosynthesis, and the PS II reaction center is especially susceptible to photo-oxidative damage. Therefore, oxygenic photosynthetic organisms have evolved an elaborate but efficient system for repairing PS II that involves selective degradation of damaged proteins (primarily D1) and incorporation of newly synthesized proteins to reconstitute 
functional PS II (13). Under some circumstances, damaged PS II reaction centers may also be sites of thermal dissipation (qI) $(92,116)$.

The repair of PS II is an important photoprotective mechanism, because the rate of repair must match the rate of damage to avoid photoinhibition resulting from net loss of functional PS II centers. Therefore, continual new synthesis of chloroplast-encoded proteins, especially D1, is critical for photoprotection at all light intensities. Blocking chloroplast protein synthesis with inhibitors during exposure of algae or plants to light results in photoinhibition and net loss of D1 protein (for example, see 19, 146). Similarly, attenuation of chloroplast protein synthesis in rRNA mutants of Chlamydomonas leads to chronic photoinhibition and lower levels of D1 during growth in high light (73). To analyze the effect of a specific limitation of D1 synthesis, rather than a general inhibition of all chloroplast protein synthesis, it may be possible to isolate partial loss-offunction alleles of mutations such as Chlamydomonas F35, which specifically affects expression of D1 (157).

Other factors involved in repair of PS II are being identified by various genetic approaches. A screen for Chlamydomonas mutants that are more sensitive to PS II photodamage has uncovered mutants that may be defective in PS II repair, including a mutant that accumulates more D1 protein than wild type (158). A possible role for the $p s b T$ gene (originally known as $y c f 8$ ) in the chloroplast genome of Chlamydomonas in protection of PS II in high light has been suggested by characterization of a $p s b T$ disruption mutant (105). In transgenic tobacco plants, decreasing the unsaturation of chloroplast glycerolipids results in greater sensitivity to low-temperature photoinhibition, apparently because of inhibition of PS II repair (106).

\section{CONCLUSIONS AND PROSPECTS}

Photoprotection of photosynthesis is a balancing act. Thermal dissipation and alternative electron transport pathways, together with changes in antenna size and overall photosynthetic capacity, help to balance light absorption and utilization in the constantly changing natural environment. The generation of reactive oxygen species is balanced by the capacity of antioxidant systems. The capacity for repair must match the damage that is not prevented by other photoprotective processes.

Multiple, partially redundant mechanisms acting in concert help to prevent net photo-oxidative damage that results from generation of reactive molecules through photosynthesis. The redundancy is not surprising given how critical photoprotection is for fitness and survival of algae and plants in most environments. Indeed, many of the molecules and enzymes involved in photoprotection have roles in more than one photoprotective mechanism. For 
example, xanthophylls are involved in both thermal dissipation and quenching of ${ }^{1} \mathrm{O}_{2}$, whereas SOD and APX enzymes scavenge reactive oxygen species while maintaining electron transport via the water-water cycle.

The use of molecular genetic approaches to study photoprotection is just beginning, but the potential for rapid progress is obvious. Mutants affecting many chloroplast processes are now available, and assessment of their relative importance for photoprotection is under way in several laboratories. Because photoprotective processes comprise several lines of defense against the damaging effects of light, construction of double and perhaps even triple mutants in some cases may be necessary in order to obtain clear phenotypes. In the future, other genetic approaches, such as screening for suppressors or enhancers of these phenotypes, may uncover previously unrecognized mechanisms of photoprotection.

\section{ACKNOWLEDGMENTS}

I thank Anastasios Melis and Catharina Casper-Lindley for comments on the manuscript and Dan Kliebenstein and Dean DellaPenna for communicating unpublished results. Unpublished work in the author's laboratory is supported by grants from the Searle Scholars Program/The Chicago Community Trust and the USDA NRICGP (\#9801685).

Visit the Annual Reviews home page at http://www.AnnualReviews.org

\section{Literature Cited}

1. Alizadeh S, Nechushtai R, Barber J, Nixon P. 1994. Nucleotide sequence of the $p s b E, p s b F$ and $t r n M$ genes from the chloroplast genome of Chlamydomonas reinhardtii. Biochim. Biophys. Acta 1188:439-42

2. Allen JF. 1995. Thylakoid protein phosphorylation, state 1-state 2 transitions, and photosystem stoichiometry adjustment: redox control at multiple levels of gene expression. Physiol. Plant. 93: 196-205

3. Allen RD. 1995. Dissection of oxidative stress tolerance using transgenic plants. Plant Physiol. 107:1049-54

4. Allen RD, Webb RP, Schake SA. 1997. Use of transgenic plants to study antioxidant defenses. Free Rad. Biol. Med. 23:473-79

5. Alscher RG, Donahue JL, Cramer CL. 1997. Reactive oxygen species and antioxidants: relationships in green cells. Physiol. Plant. 100:224-33
6. Anderson IC, Robertson DS. 1960. Role of carotenoids in protecting chlorophyll from photodestruction. Plant Physiol. 35:531-34

7. Anderson JM. 1986. Photoregulation of the composition, function and structure of thylakoid membranes. Annu. Rev. Plant Physiol. 37:93-136

8. Anderson JM, Andersson B. 1988. The dynamic photosynthetic membrane and regulation of solar energy conversion. Trends Biochem. Sci. 13:351-55

9. Anderson JM, Park Y-I, Chow WS. 1997. Photoinactivation and photoprotection of photosystem II in nature. Physiol. Plant. 100:214-23

10. Anderson JM, Park Y-I, Chow WS. 1998. Unifying model for the photoinactivation of Photosystem II in vivo under steady-state photosynthesis. Photosynth. Res. 56:1-13

11. Andersson B, Barber J. 1996. Mechanisms of photodamage and protein 
degradation during photoinhibition of photosystem II. See Ref. 17a, pp. 10121

12. Andrews JR, Fryer MJ, Baker NR. 1995. Consequences of LHC II deficiency for photosynthetic regulation in chlorina mutants of barley. Photosynth. Res. 44:81-91

13. Aro E-M, Virgin I, Andersson B. 1993. Photoinhibition of photosystem II. Inactivation, protein damage and turnover. Biochim. Biophys. Acta 1143:113-34

14. Artus NN, Somerville SC, Somerville CR. 1986. The biochemistry and cell biology of photorespiration. CRC Crit. Rev. Plant Sci. 4:121-47

15. Asada K. 1994. Mechanisms for scavenging reactive molecules generated in chloroplasts under light stress. See Ref. $17 \mathrm{~b}$, pp. 129-42

16. Asada K. 1994. Production and action of active oxygen species in photosynthetic tissues. In Causes of Photooxidative Stress and Amelioration of Defense Systems in Plants, ed. CH Foyer, PM Mullineaux, pp. 77-104. Boca Raton: CRC Press

17. Asada K. 1999. The water-water cycle. Annu. Rev. Plant Physiol. Plant Mol. Biol. 50:601-39

17a. Baker NR, ed. 1996. Photosynthesis and the Environment. Dordrecht: Kluwer

17b. Baker NR, Bowyer JR, eds. 1994. Photoinhibition of Photosynthesis: From Molecular Mechanisms to the Field. Oxford: BIOS Sci. Publ.

18. Barber J, Andersson B. 1992. Too much of a good thing: Light can be bad for photosynthesis. Trends Biochem. Sci. 17:61-66

19. Baroli I, Melis A. 1996. Photoinhibition and repair in Dunaliella salina acclimated to different growth irradiances. Planta 198:640-46

20. Baroli I, Melis A. 1998. Photoinhibitory damage is modulated by the rate of photosynthesis and by the photosystem II light-harvesting chlorophyll antenna size. Planta 205:288-96

21. Bendall DS, Manasse RS. 1995. Cyclic photophosphorylation and electron transport. Biochim. Biophys. Acta 1229: 23-38

22. Biehler K, Fock H. 1996. Evidence for the contribution of the Mehler-peroxidase reaction in dissipating excess electrons in drought-stressed wheat. Plant Physiol. 112:265-72

23. Bilger W, Björkman O. 1990. Role of the xanthophyll cycle in photoprotection elucidated by measurements of light- induced absorbance changes, fluorescence and photosynthesis in leaves of Hedera canariensis. Photosynth. Res. 25:173-85

24. Bilger W, Björkman O. 1994. Relationships among violaxanthin deepoxidation, thylakoid membrane conformation, and nonphotochemical chlorophyll fluorescence quenching in leaves of cotton (Gossypium hirsutum L.). Planta 193:238-46

25. Bilger W, Björkman O, Thayer SS. 1989. Light-induced spectral absorbance changes in relation to photosynthesis and the epoxidation state of xanthophyll cycle components in cotton leaves. Plant Physiol. 91:542-51

26. Bishop NI. 1996. The $\beta, \varepsilon$-carotenoid, lutein, is specifically required for the formation of the oligomeric forms of the light harvesting complex in the green alga, Scenedesmus obliquus. J. Photochem. Photobiol. B: Biol. 36:279-83

27. Bishop NI, Bugla B, Senger H. 1998. Photosynthetic capacity and quantum requirement of three secondary mutants of Scenedesmus obliquus with deletions in carotenoid biosynthesis. Bot. Acta 111: 231-35

28. Bishop NI, Urbig T, Senger H. 1995. Complete separation of the $\beta, \varepsilon$ - and $\beta, \beta$ carotenoid biosynthetic pathways by a unique mutation of the lycopene cyclase in the green alga, Scenedesmus obliquus. FEBS Lett. 367:158-62

29. Bishop NI, Wong J. 1974. Photochemical characteristics of a vitamin E deficient mutant of Scenedesmus obliquus. Ber. Dtsch. Bot. Ges. 87:359-71

30. Björkman O. 1981. Responses to different quantum flux densities. In Physiological Plant Ecology I. Responses to the Physical Environment, ed. OL Lange, PS Nobel, CB Osmond, H Ziegler, pp. 57-107. Berlin: Springer-Verlag

31. Björkman O, Demmig-Adams B. 1994. Regulation of photosynthetic light energy capture, conversion, and dissipation in leaves of higher plants. In Ecophysiology of Photosynthesis, ed. E-D Schulze, MM Caldwell, pp. 17-47. Berlin: Springer

32. Bossmann B, Knoetzel J, Jansson S. 1997. Screening of chlorina mutants of barley (Hordeum vulgare L.) with antibodies against light-harvesting proteins of PS I and PS II: absence of specific antenna proteins. Photosynth. Res. 52: $127-36$

33. Bowler C, Van Camp W, Van Montagu M, Inzé D. 1994. Superoxide dismutase 
in plants. Crit. Rev. Plant Sci. 13:199218

34. Briantais J-M. 1994. Light-harvesting chlorophyll $a-b$ complex requirement for regulation of Photosystem II photochemistry by non-photochemical quenching. Photosynth. Res. 40:287-94

35. Bugos RC, Hieber AD, Yamamoto HY. 1998. Xanthophyll cycle enzymes are members of the lipocalin family, the first identified from plants. J. Biol. Chem. 273:15321-24

36. Burrows PA, Sazanov LA, Svab Z, Maliga P, Nixon PJ. 1998. Identification of a functional respiratory complex in chloroplasts through analysis of tobacco mutants containing disrupted plastid $n d h$ genes. EMBO J. 17:868-76

37. Chow WS. 1994. Photoprotection and photoinhibitory damage. In Advances in Molecular and Cell Biology, ed. EE Bittar, J Barber, 10:151-96. London: JAI Press

38. Chunaev AS, Mirnaya ON, Maslov VG, Boschetti A. 1991. Chlorophyll $b$ - and loroxanthin-deficient mutants of Chlamydomonas reinhardtii. Photosynthetica 25:291-301

39. Cobbett CS, May MJ, Howden R, Rolls B. 1998. The glutathione-deficient, cadmium-sensitive mutant, cad2-1, of Arabidopsis thaliana is deficient in $\gamma$ glutamylcysteine synthetase. Plant $J$. 16:73-78

40. Conklin PL, Pallanca JE, Last RL, Smirnoff N. 1997. L-ascorbic acid metabolism in the ascorbate-deficient Arabidopsis mutant vtcl. Plant Physiol. 115:1277-85

41. Conklin PL, Williams EH, Last RL. 1996. Environmental stress sensitivity of an ascorbic acid-deficient Arabidopsis mutant. Proc. Natl. Acad. Sci. USA 93:9970-74

42. Crofts AR, Yerkes CT. 1994. A molecular mechanism for $\mathrm{q}_{\mathrm{E}}$-quenching. $F E B S$ Lett. 352:265-70

43. Cunningham FX Jr, Gantt E. 1998. Genes and enzymes of carotenoid biosynthesis in plants. Annu. Rev. Plant Physiol. Plant Mol. Biol. 49:557-83

44. Dau H. 1994. Molecular mechanisms and quantitative models of variable photosystem II fluorescence. Photochem. Photobiol. 60:1-23

45. de Jesus MD, Tabatabai F, Chapman DJ. 1989. Taxonomic distribution of copperzinc superoxide dismutase in green algae and its phylogenetic importance. J. Phycol. 25:767-72

46. Demmig B, Cleland RE, Björkman O.
1987. Photoinhibition, 77K chlorophyll fluorescence quenching and phosphorylation of the light-harvesting chlorophyll-protein complex of photosystem II in soybean leaves. Planta 172:37885

47. Demmig-Adams B. 1990. Carotenoids and photoprotection in plants: a role for the xanthophyll zeaxanthin. Biochim. Biophys. Acta 1020:1-24

48. Demmig-Adams B, Adams WW III. 1992. Photoprotection and other responses of plants to high light stress. Annu. Rev. Plant Physiol. Plant Mol. Biol. 43:599-626

49. Demmig-Adams B, Adams WW III. 1996. The role of xanthophyll cycle carotenoids in the protection of photosynthesis. Trends Plant Sci. 1:21-26

50. Demmig-Adams B, Adams WW III, Barker DH, Logan BA, Bowling DR, Verhoeven AS. 1996. Using chlorophyll fluorescence to assess the fraction of absorbed light allocated to thermal dissipation of excess excitation. Physiol. Plant. 98:253-64

51. Demmig-Adams B, Gilmore AM, Adams WW III. 1996. In vivo functions of carotenoids in higher plants. FASEB J. 10:403-12

52. Demmig-Adams B, Moeller DL, Logan BA, Adams WW III. 1998. Positive correlation between levels of retained zeaxanthin + antheraxanthin and degree of photoinhibition in shade leaves of Schefflera arboricola (Hayata) Merrill. Planta 205:367-74

53. Duckham SC, Linforth RST, Taylor IB. 1991. Abscisic-acid-deficient mutants at the aba gene locus of Arabidopsis thaliana are impaired in the epoxidation of zeaxanthin. Plant Cell Environ. 14:601-6

54. Escoubas J-M, Lomas M, LaRoche J, Falkowski PG. 1995. Light intensity regulation of $c a b$ gene transcription is signaled by the redox state of the plastoquinone pool. Proc. Natl. Acad. Sci. USA 92:10237-41

55. Eskling M, Arvidsson P-O, Åkerlund H-E. 1997. The xanthophyll cycle, its regulation and components. Physiol. Plant. 100:806-16

56. Foote CS. 1976. Photosensitized oxidation and singlet oxygen: consequences in biological systems. In Free Radicals in Biology, ed. WA Pryor, 2:85-133. New York: Academic

57. Foyer $\mathrm{CH}$, Descourvières $\mathrm{P}$, Kunert KJ. 1994. Protection against oxygen radicals: an important defence mechanism 
studied in transgenic plants. Plant Cell Environ. 17:507-23

58. Foyer CH, Harbinson J. 1994. Oxygen metabolism and the regulation of photosynthetic electron transport. In Causes of Photooxidative Stress and Amelioration of Defense Systems in Plants, ed. CH Foyer, PM Mullineaux, pp. 1-42. Boca Raton: CRC Press

59. Foyer $\mathrm{CH}$, Lelandais $\mathrm{M}$, Kunert $\mathrm{KJ}$. 1994. Photooxidative stress in plants. Physiol. Plant. 92:696-717

60. Frank HA, Cogdell RJ. 1993. The photochemistry and function of carotenoids in photosynthesis. In Carotenoids in Photosynthesis, ed. A Young, G Britton, pp. 252-326. London: Chapman \& Hall

61. Frank HA, Cogdell RJ. 1996. Carotenoids in photosynthesis. Photochem. Photobiol. 63:257-64

62. Frank HA, Cua A, Chynwat V, Young A, Gosztola D, Wasielewski MR. 1994. Photophysics of the carotenoids associated with the xanthophyll cycle in photosynthesis. Photosynth. Res. 41:389-95

63. Friedrich T, Steinmüller K, Weiss H. 1995. The proton-pumping respiratory complex I of bacteria and mitochondria and its homologue in chloroplasts. FEBS Lett. 367:107-11

64. Fryer MJ. 1992. The antioxidant effects of thylakoid Vitamin E ( $\alpha$-tocopherol). Plant Cell Environ. 15:381-92

65. Gilmore AM. 1997. Mechanistic aspects of xanthophyll cycle-dependent photoprotection in higher plant chloroplasts and leaves. Physiol. Plant. 99:197-209

66. Gilmore AM, Hazlett TL, Debrunner PG, Govindjee. 1996. Photosystem II chlorophyll $a$ fluorescence lifetimes and intensity are independent of the antenna size differences between barley wildtype and chlorina mutants: photochemical quenching and xanthophyll cycledependent nonphotochemical quenching of fluorescence. Photosynth. Res. 48: 171-87

67. Grace SC, Logan BA. 1996. Acclimation of foliar antioxidant systems to growth irradiance in three broadleaved evergreen species. Plant Physiol. 112:1631-40

68. Härtel H, Lokstein H. 1995. Relationship between quenching of maximum and dark-level chlorophyll fluorescence in vivo: dependence on Photosystem II antenna size. Biochim. Biophys. Acta 1228:91-94

69. Härtel H, Lokstein H, Grimm B, Rank B. 1996. Kinetic studies on the xanthophyll cycle in barley leaves. Influence of antenna size and relations to nonphotochemical chlorophyll fluorescence quenching. Plant Physiol. 110:471-82

70. Havaux M. 1998. Carotenoids as membrane stabilizers in chloroplasts. Trends Plant Sci. 3:147-51

71. Heber U, Bligny R, Streb P, Douce R. 1996. Photorespiration is essential for the protection of the photosynthetic apparatus of $\mathrm{C} 3$ plants against photoinactivation under sunlight. Bot. Acta 109:307-15

72. Heber U, Walker D. 1992. Concerning a dual function of coupled cyclic electron transport in leaves. Plant Physiol. 100:1621-26

73. Heifetz PB, Lers A, Turpin DH, Gillham NW, Boynton JE, Osmond CB. 1997. $d r$ and $\mathrm{spr} / \mathrm{sr}$ mutations of Chlamydomonas reinhardtii affecting D1 protein function and synthesis define two independent steps leading to chronic photoinhibition and confer differential fitness. Plant Cell Environ. 20:1145-57

74. Henry A, Powls R, Pennock JF. 1986. Scenedesmus obliquus PS28: a tocopherol-free mutant which cannot form phytol. Biochem. Soc. Trans. 14:95859

75. Horton P, Ruban AV. 1994. The role of light-harvesting complex II in energy quenching. See Ref. 17b, pp. 111-28

76. Horton P, Ruban AV, Walters RG. 1994. Regulation of light harvesting in green plants. Indication by nonphotochemical quenching of chlorophyll fluorescence. Plant Physiol. 106:415-20

77. Horton P, Ruban AV, Walters RG. 1996. Regulation of light harvesting in green plants. Annu. Rev. Plant Physiol. Plant Mol. Biol. 47:655-84

78. Howden R, Andersen CR, Goldsbrough PB, Cobbett CS. 1995. A cadmium-sensitive, glutathione-deficient mutant of Arabidopsis. Plant Physiol. 107:106773

79. Huner NPA, Öquist G, Sarhan F. 1998. Energy balance and acclimation to light and cold. Trends Plant Sci. 3:224-30

80. Hurry V, Anderson JM, Badger MR, Price GD. 1996. Reduced levels of cytochrome $b_{6} / f$ in transgenic tobacco increases the excitation pressure on photosystem II without increasing the sensitivity to photoinhibition in vivo. Photosynth. Res. 50:159-69

81. Hurry V, Anderson JM, Chow WS, Osmond CB. 1997. Accumulation of zeaxanthin in abscisic acid-deficient mutants of Arabidopsis does not affect chlorophyll fluorescence quenching or 
sensitivity to photoinhibition in vivo. Plant Physiol. 113:639-48

82. Jahns P, Miehe B. 1996. Kinetic correlation of recovery from photoinhibition and zeaxanthin epoxidation. Planta 198:202-10

83. Jespersen HM, Kjaersgard IVH, Ostergaard L, Welinder KG. 1997. From sequence analysis of three novel ascorbate peroxidases from Arabidopsis thaliana to structure, function and evolution of seven types of ascorbate peroxidase. Biochem. J. 326:305-10

84. Kaiser WM. 1979. Reversible inhibition of the Calvin cycle and activation of oxidative pentose phosphate cycle in isolated intact chloroplasts by hydrogen peroxide. Planta 145:377-82

85. Kitayama K, Kitayama M, Togasaki RK. 1995. Characterization of paraquatresistant mutants of Chlamydomonas reinhardtii. In Photosynthesis: From Light to Biosphere, ed. P Mathis, 3:595-98. Dordrecht: Kluwer

86. Kliebenstein DJ, Monde R-A, Last RL. 1998. Superoxide dismutase in Arabidopsis: an eclectic enzyme family with disparate regulation and protein localization. Plant Physiol. 118:637-50

87. Knox JP, Dodge AD. 1985. Singlet oxygen and plants. Phytochemistry 24:88996

88. Kofer W, Koop H-U, Wanner G, Steinmüller K. 1998. Mutagenesis of the genes encoding subunits A, C, H, I, J and $\mathrm{K}$ of the plastid NAD(P)H-plastoquinone-oxidoreductase in tobacco by polyethylene glycol-mediated plastome transformation. Mol. Gen. Genet. 258:166-73

89. Kok B. 1956. On the inhibition of photosynthesis by intense light. Biochim. Biophys. Acta 21:234-44

90. Koornneef M, Jorna ML, Brinkhorst-van der Swan DLC, Karssen CM. 1982. The isolation of abscisic acid (ABA) deficient mutants by selection of induced revertants in non-germinating gibberellin sensitive lines of Arabidopsis thaliana (L.) Heynh. Theor. Appl. Genet. 61:38593

91. Kozaki A, Takeba G. 1996. Photorespiration protects $\mathrm{C} 3$ plants from photooxidation. Nature 384:557-60

92. Krause GH. 1988. Photoinhibition of photosynthesis. An evaluation of damaging and protective mechanisms. Physiol. Plant. 74:566-74

93. Król M, Spangfort MD, Huner NPA, Öquist G, Gustafsson P, Jansson S. 1995. Chlorophyll $a / b$-binding proteins, pigment conversions, and early lightinduced proteins in a chlorophyll $b$-less barley mutant. Plant Physiol. 107:87383

94. Kühlbrandt W, Wang DN, Fujiyoshi Y. 1994. Atomic model of plant lightharvesting complex by electron crystallography. Nature 367:614-21

95. Levine RP. 1969. The analysis of photosynthesis using mutant strains of algae and higher plants. Annu. Rev. Plant Physiol. 20:523-40

96. Lindahl M, Yang D-H, Andersson B. 1995. Regulatory proteolysis of the major light-harvesting chlorophyll $a-b$ protein of photosystem II by a light-induced membrane-associated enzymic system. Eur. J. Biochem. 231:503-9

97. Lokstein $H$, Härtel $H$, Hoffmann $P$, Renger G. 1993. Comparison of chlorophyll fluorescence quenching in leaves of wild-type with a chlorophyll-b-less mutant of barley (Hordeum vulgare L.). J. Photochem. Photobiol. B: Biol. 19: 217-25

98. Long SP, Humphries S, Falkowski PG. 1994. Photoinhibition of photosynthesis in nature. Annu. Rev. Plant Physiol. Plant Mol. Biol. 45:633-62

99. Lovelock CE, Winter K. 1996. Oxygendependent electron transport and protection from photoinhibition in leaves of tropical tree species. Planta 198:580-87

100. Marin E, Nussaume L, Quesada A, Gonneau M, Sotta B, et al. 1996. Molecular identification of zeaxanthin epoxidase of Nicotiana plumbaginifolia, a gene involved in abscisic acid biosynthesis and corresponding to the $A B A$ locus of Arabidopsis thaliana. EMBO J. $15: 2331-42$

101. Maxwell DP, Laudenbach DE, Huner NPA. 1995. Redox regulation of lightharvesting complex II and $c a b$ mRNA abundance in Dunaliella salina. Plant Physiol. 109:787-95

102. Mehler AH. 1951. Studies on reactions of illuminated chloroplasts. I. Mechanism of the reduction of oxygen and other Hill reagents. Arch. Biochem. Biophys. 33:65-77

103. Melis A. 1991. Dynamics of photosynthetic membrane composition and function. Biochim. Biophys. Acta 1058:87106

104. Miyake C, Asada K. 1992. Thylakoidbound ascorbate peroxidase in spinach chloroplasts and photoreduction of its primary oxidation product mondehydroascorbate radicals in thylakoids. Plant Cell Physiol. 33:541-53 
105. Monod C, Takahashi Y, GoldschmidtClermont M, Rochaix J-D. 1994. The chloroplast $y c f 8$ open reading frame encodes a photosystem II polypeptide which maintains photosynthetic activity under adverse growth conditions. $E M B O$ J. 13:2747-54

106. Moon BY, Higashi S-I, Gombos Z, Murata N. 1995. Unsaturation of the membrane lipids of chloroplasts stabilizes the photosynthetic machinery against low-temperature photoinhibition in transgenic tobacco plants. Proc. Natl. Acad. Sci. USA 92:6219-23

107. Mor TS, Ohad I, Hirschberg J, Pakrasi H. 1995. An unusual organization of the genes encoding cytochrome b-559 in Chlamydomonas reinhardtii: $p s b E$ and $p s b F$ are separately transcribed from different regions of the plastid chromosome. Mol. Gen. Genet. 246:600-4

108. Murray DL, Kohorn BD. 1991. Chloroplasts of Arabidopsis thaliana homozygous for the ch-1 locus lack chlorophyll $b$, lack stable LHCPII and have stacked thylakoids. Plant Mol. Biol. 16:71-79

109. Niyogi KK, Björkman O, Grossman AR. 1997. Chlamydomonas xanthophyll cycle mutants identified by video imaging of chlorophyll fluorescence quenching. Plant Cell 9:1369-80

110. Niyogi KK, Björkman O, Grossman AR. 1997. The roles of specific xanthophylls in photoprotection. Proc. Natl. Acad. Sci. USA 94:14162-67

111. Niyogi KK, Grossman AR, Björkman O. 1998. Arabidopsis mutants define a central role for the xanthophyll cycle in the regulation of photosynthetic energy conversion. Plant Cell 10:1121-34

112. Noctor G, Foyer CH. 1998. Ascorbate and glutathione: keeping active oxygen under control. Annu. Rev. Plant Physiol. Plant Mol. Biol. 49:249-79

113. Norris SR, Barrette TR, DellaPenna D. 1995. Genetic dissection of carotenoid synthesis in Arabidopsis defines plastoquinone as an essential component of phytoene desaturation. Plant Cell 7:2139-49

114. Ogawa K, Kanematsu S, Takabe K, Asada K. 1995. Attachment of CuZnsuperoxide dismutase to thylakoid membranes at the site of superoxide generation (PSI) in spinach chloroplasts: detection by immuno-gold labeling after rapid freezing and substitution method. Plant Cell Physiol. 36:565-73

115. Ohad I, Keren N, Zer H, Gong H, Mor TS, et al. 1994. Light-induced degradation of the photosystem II reaction centre
D1 protein in vivo: an integrative approach. See Ref. 17b, pp. 161-77

116. Öquist G, Chow WS, Anderson JM. 1992. Photoinhibition of photosynthesis represents a mechanism for the long-term regulation of photosystem II. Planta 186:450-60

117. Osmond CB. 1981. Photorespiration and photoinhibition: some implications for the energetics of photosynthesis. Biochim. Biophys. Acta 639:77-98

118. Osmond CB. 1994. What is photoinhibition? Some insights from comparisons of shade and sun plants. See Ref. 17b, pp. $1-24$

119. Osmond CB, Grace SC. 1995. Perspectives on photoinhibition and photorespiration in the field: quintessential inefficiencies of the light and dark reactions of photosynthesis? J. Exp. Bot. 46:135162

120. Owens TG. 1994. Excitation energy transfer between chlorophylls and carotenoids. A proposed molecular mechanism for non-photochemical quenching. See Ref. 17b, pp. 95-109

121. Owens TG. 1996. Processing of excitation energy by antenna pigments. See Ref. 17a, pp. 1-23

122. Park Y-I, Anderson JM, Chow WS. 1996. Photoinactivation of functional photosystem II and D1-protein synthesis in vivo are independent of the modulation of the photosynthetic apparatus by growth irradiance. Planta 198:300-9

123. Park Y-I, Chow WS, Anderson JM. 1995. Light inactivation of functional photosystem II in leaves of peas grown in moderate light depends on photon exposure. Planta 196:401-11

124. Park Y-I, Chow WS, Osmond CB, Anderson JM. 1996. Electron transport to oxygen mitigates against the photoinactivation of Photosystem II in vivo. Photosynth. Res. 50:23-32

125. Pfündel E, Bilger W. 1994. Regulation and possible function of the violaxanthin cycle. Photosynth. Res. 42:89-109

126. Pogson B, McDonald KA, Truong M, Britton G, DellaPenna D. 1996. Arabidopsis carotenoid mutants demonstrate that lutein is not essential for photosynthesis in higher plants. Plant Cell 8:1627-39

127. Pogson BJ, Niyogi KK, Björkman O, DellaPenna D. 1998. Altered xanthophyll compositions adversely affect chlorophyll accumulation and nonphotochemical quenching in Arabidopsis mutants. Proc. Natl. Acad. Sci. USA 95: 13324-29 
128. Polle A. 1997. Defense against photooxidative damage in plants. In Oxidative Stress and the Molecular Biology of Antioxidant Defenses, ed. JG Scandalios, pp. 623-66. Plainview, NY: Cold Spring Harbor Lab. Press

129. Powles SB. 1984. Photoinhibition of photosynthesis induced by visible light. Annu. Rev. Plant Physiol. 35:14-44

130. Rintamäki E, Salonen M, Suoranta U-M, Carlberg I, Andersson B, Aro E-M. 1997. Phosphorylation of light-harvesting complex II and photosystem II core proteins shows different irradiancedependent regulation in vivo. J. Biol. Chem. 272:30476-82

131. Rock CD, Zeevaart JAD. 1991. The $a b a$ mutant of Arabidopsis thaliana is impaired in epoxy-carotenoid biosynthesis. Proc. Natl. Acad. Sci. USA 88:749699

132. Ruban AV, Young AJ, Horton P. 1993. Induction of nonphotochemical energy dissipation and absorbance changes in leaves. Evidence for changes in the state of the light-harvesting system of photosystem II in vivo. Plant Physiol. 102:741-50

133. Sager R, Zalokar M. 1958. Pigments and photosynthesis in a carotenoiddeficient mutant of Chlamydomonas. Nature 182:98-100

134. Schatz G, Brock H, Holzwarth AR. 1988. Kinetic and energetic model for the primary processes in photosystem II. Biophys. J. 54:397-405

135. Schreiber U, Neubauer C. $1990 . \mathrm{O}_{2-}$ dependent electron flow, membrane energization and the mechanism of nonphotochemical quenching of chlorophyll fluorescence. Photosynth. Res. 25: 279-93

136. Schuster G, Dewit M, Staehelin LA, Ohad I. 1986. Transient inactivation of the thylakoid photosystem II lightharvesting protein kinase system and concomitant changes in intramembrane particle size during photoinhibition of Chlamydomonas reinhardtii. J. Cell Biol. 103:71-80

137. Sen Gupta A, Heinen JL, Holaday AS, Burke JJ, Allen RD. 1993. Increased resistance to oxidative stress in transgenic plants that overexpress chloroplastic $\mathrm{Cu} / \mathrm{Zn}$ superoxide dismutase. Proc. Natl. Acad. Sci. USA 90:1629-33

138. Sen Gupta A, Webb RP, Holaday AS, Allen RD. 1993. Overexpression of superoxide dismutase protects plants from oxidative stress. Induction of ascorbate peroxidase in superoxide dismutase- overexpressing plants. Plant Physiol. 103:1067-73

139. Shikanai T, Endo T, Hashimoto T, Yamada Y, Asada K, Yokota A. 1998. Directed disruption of the tobacco $n d h B$ gene impairs cyclic electron flow around photosystem I. Proc. Natl. Acad. Sci. USA 95:9705-9

140. Shikanai T, Shimizu K, Endo T, Hashimoto T. 1998. Screening of Arabidopsis mutants lacking down-regulation of photosystem II using an imaging system of chlorophyll fluorescence. In Photosynthesis: Mechanisms and Effects, ed. G Garah. Dordrecht: Kluwer. In press

140a. Shintani D, DellaPenna D. 1998. Elevating the vitamin $\mathrm{E}$ content of plants through metabolic engineering. Science 282:2098-100

141. Smirnoff N. 1996. The function and metabolism of ascorbic acid in plants. Ann. Bot. 78:661-69

142. Somerville CR. 1986. Analysis of photosynthesis with mutants of higher plants and algae. Annu. Rev. Plant Physiol. 37: 467-507

143. Sonoike K. 1996. Photoinhibition of photosystem I: its physiological significance in the chilling sensitivity of plants. Plant Cell Physiol. 37:239-47

144. Tardy F, Havaux M. 1996. Photosynthesis, chlorophyll fluorescence, lightharvesting system and photoinhibition resistance of a zeaxanthin-accumulating mutant of Arabidopsis thaliana. J. Photochem. Photobiol. B: Biol. 34:8794

145. Telfer A, Dhami S, Bishop SM, Phillips D, Barber J. 1994. $\beta$-carotene quenches singlet oxygen formed by isolated photosystem II reaction centers. Biochemistry 33:14469-74

146. Tyystjärvi E, Aro E-M. 1996. The rate constant of photoinhibition, measured in lincomycin-treated leaves, is directly proportional to light intensity. Proc. Natl. Acad. Sci. USA 93:2213-18

147. Van Camp W, Capiau K, Van Montagu M, Inzé D, Slooten L. 1996. Enhancement of oxidative stress tolerance in transgenic tobacco plants overproducing Fe-superoxide dismutase in chloroplasts. Plant Physiol. 112:1703-14

148. Vass I, Styring S, Hundal T, Koivuniemi A, Aro E-M, Andersson B. 1992. Reversible and irreversible intermediates during photoinhibition of photosystem II: Stable reduced $\mathrm{Q}_{\mathrm{A}}$ species promote chlorophyll triplet formation. Proc. Natl. Acad. Sci. USA 89:1408-12

149. Wallsgrove RM, Turner JC, Hall NP, 
Kendall AC, Bright SWJ. 1987. Barley mutants lacking chloroplast glutamine synthetase-biochemical and genetic analysis. Plant Physiol. 83:155-58

150. Walters RG, Horton P. 1994. Acclimation of Arabidopsis thaliana to the light environment: changes in composition of the photosynthetic apparatus. Planta 195:248-56

151. Walters RG, Ruban AV, Horton P. 1994. Higher plant light-harvesting complexes LHCIIa and LHCIIc are bound by dicyclohexylcarbodiimide during inhibition of energy dissipation. Eur. J. Biochem. 226:1063-69

152. Walters RG, Ruban AV, Horton P. 1996. Identification of proton-active residues in a higher plant light-harvesting complex. Proc. Natl. Acad. Sci. USA 93: 14204-9

153. Wheeler GL, Jones MA, Smirnoff N. 1998. The biosynthetic pathway of vitamin C in higher plants. Nature 393: 365-69

154. Whitmarsh J, Samson G, Poulson M. 1994. Photoprotection in photosystem
II-the role of cytochrome $b 559$. See Ref. 17b, pp. 75-93

155. Wiese C, Shi L-B, Heber U. 1998. Oxygen reduction in the Mehler reaction is insufficient to protect photosystems I and II of leaves against photoinactivation. Physiol. Plant. 102:437-46

156. Winter K, Königer M. 1989. Dithiothreitol, an inhibitor of violaxanthin deepoxidation, increases the susceptibility of leaves of Nerium oleander L. to photoinhibition of photosynthesis. Planta 180:24-31

157. Yohn CB, Cohen A, Danon A, Mayfield SP. 1996. Altered mRNA binding activity and decreased translation initiation in a nuclear mutant lacking translation of the chloroplast $p s b A$ mRNA. Mol. Cell. Biol. 16:3560-66

158. Zhang L, Niyogi KK, Baroli I, Nemson JA, Grossman AR, Melis A. 1997. DNA insertional mutagenesis for the elucidation of a Photosystem II repair process in the green alga Chlamydomonas reinhardtii. Photosynth. Res. 53:17384 